\title{
Article \\ Secreted Trimeric Chikungunya Virus Spikes from Insect Cells: Production, Purification, and Glycosylation Status
}

\author{
Tessy A. H. Hick ${ }^{1}{ }^{\mathbb{D}}$, Corinne Geertsema ${ }^{1}$, Maurice G. L. Henquet ${ }^{2}$, Dirk E. Martens ${ }^{3}$, Stefan W. Metz ${ }^{1}$ \\ and Gorben P. Pijlman $1, *$ (D)
}

1 Laboratory of Virology, Wageningen University and Research, 6708PB Wageningen, The Netherlands; tessy.hick@wur.nl (T.A.H.H.); corinne.geertsema@wur.nl (C.G.); metzs@ebsi.com (S.W.M.)

2 Business Unit Bioscience, Wageningen University and Research, 6708PB Wageningen, The Netherlands; maurice.henquet@wur.nl

3 Bioprocess Engineering, Wageningen University and Research, 6708PB Wageningen, The Netherlands; dirk.martens@wur.nl

* Correspondence: gorben.pijlman@wur.nl

check for

updates

Citation: Hick, T.A.H.; Geertsema, C.; Henquet, M.G.L.; Martens, D.E.; Metz, S.W.; Pijlman, G.P. Secreted Trimeric Chikungunya Virus Spikes from Insect Cells: Production, Purification, and Glycosylation Status. Processes 2022, 10, 162 . https://doi.org/10.3390/pr10010162 Academic Editors: Tzong-Yuan Wu, Monique M. van Oers and Li-Fen Huang

Received: 21 December 2021

Accepted: 11 January 2022

Published: 14 January 2022

Publisher's Note: MDPI stays neutral with regard to jurisdictional claims in published maps and institutional affiliations.

Copyright: (C) 2022 by the authors. Licensee MDPI, Basel, Switzerland. This article is an open access article distributed under the terms and conditions of the Creative Commons Attribution (CC BY) license (https:// creativecommons.org/licenses/by/ $4.0 /)$.

\begin{abstract}
Chikungunya virus (CHIKV) is a rapidly emerging mosquito-borne virus that causes a severe febrile illness with long-lasting arthralgia in humans. As there is no vaccine to protect humans and limit CHIKV epidemics, the virus continues to be a global public health concern. The CHIKV envelope glycoproteins E1 and E2 are important immunogens; therefore, the aim of this study is to produce trimeric CHIKV spikes in insect cells using the baculovirus expression system. The CHIKV E1 and E2 ectodomains were covalently coupled by a flexible linker that replaces the $6 \mathrm{~K}$ transmembrane protein. The C-terminal E1 transmembrane was replaced by a Strep-tag II for the purification of secreted spikes from the culture fluid. After production in Sf9 suspension cells (product yields of 5.8-7.6 mg/L), the CHIKV spikes were purified by Strep-Tactin affinity chromatography, which successfully cleared the co-produced baculoviruses. Bis(sulfosuccinimidyl)suberate crosslinking demonstrated that the spikes are secreted as trimers. PNGase F treatment showed that the spikes are glycosylated. LC-MS/MS-based glycoproteomic analysis confirmed the glycosylation and revealed that the majority are of the mannose- or hybrid-type $\mathrm{N}$-glycans and $<2 \%$ have complex-type N-glycans. The LC-MS/MS analysis also revealed three O-glycosylation sites in E1. In conclusion, the trimeric, glycosylated CHIKV spikes have been successfully produced in insect cells and are now available for vaccination studies.
\end{abstract}

Keywords: Chikungunya virus; secreted trimeric spikes; vaccine; baculovirus expression vector system; glycosylation status

\section{Introduction}

Chikungunya virus (CHIKV) is a mosquito-borne alphavirus that causes a severe febrile illness in humans. The disease is characterized by an acute stage of rash, high fever, and potentially chronic polyarthralgia [1]. As the chronic stage can persist for weeks or even years, the disease has a serious social and economic impact on patients. Over the last few years, the number of CHIKV patients increased as disease outbreaks expanded across the globe from Africa to Asia, the Americas, and Europe [2]. Further expansion of the endemic region is expected because of the increasing geographical distribution of mosquito vectors that are competent for CHIKV transmission. The expanding spread and impact of the viral infection highlight the need for an effective CHIKV vaccine. Despite many attempts, no licensed vaccine is available yet and few are in clinical testing $[3,4]$.

A promising vaccine strategy to contain the spread of CHIKV is the use of the baculovirus expression vector system (BEVS) to produce proteinaceous CHIKV vaccine antigens. BEVS allows for the rapid production of large, complex folded and post-translation modified proteins in insect cells [5-7]. As these cells can be cultured in scalable bioreactors 
and generate high product yields, the system is suitable for the large-scale production of vaccines [8-11]. Recombinant baculoviruses have previously been developed to produce a preclinical CHIKV virus-like particle (VLP) vaccine, which induced a protective neutralizing antibody response in mice after a single shot without adjuvant [12]. Unfortunately, the development of a cost-effective downstream process for this VLP vaccine was challenging as the size and biochemical properties of the contaminating, co-produced baculoviruses $(30-60 \times 250-300 \mathrm{~nm})$ were comparable to the VLP product $(70 \mathrm{~nm})$. A soluble secreted CHIKV envelope subunit antigen resolved this problem, but this antigen was less immunogenic as it lacks the correct polyprotein conformation and subsequent epitope presentation required for the induction of highly neutralizing antibodies [13]. To retain the immunogenicity of the VLP and the ease of purification of the subunit, we designed a novel BEVS-derived CHIKV protein vaccine based on secreted trimeric spikes. These spikes are smaller than VLPs and have no lipid envelop, but they have the same immunodominant viral epitope as the spikes on the wildtype virus [14].

The native CHIKV expresses its structural genes as a polyprotein (C-E3-E2-6K-E1) from which capsid $(\mathrm{C})$ is autocatalytically cleaved. The envelope (glyco)proteins (E3-E2$6 \mathrm{~K}-\mathrm{E} 1)$ are translocated to the endoplasmic reticulum (ER) and assemble as precursor heterodimer E3-E2-6K-E1 anchored in the ER membrane. In the ER, cellular signalases cleave $6 \mathrm{~K}$, resulting in the immature E3E2-E1 heterodimer [15]. This immature heterodimer is transported to the Golgi compartment and trimerized to form spikes [16]. Thereafter, the trimeric spike complexes mature further by the cellular furin cleavage of E3 [17-19]. The mature trimeric spikes are translocated to the plasma membrane where they are exposed as fusogenic transmembrane complexes until the nucleocapsid (viral RNA complex with the capsid protein) drives the budding of progeny enveloped virions.

In this study, we describe the development of a trimeric CHIKV spike vaccine antigen using BEVS in insect cells. Whereas the VLP vaccine encodes the entire structural cassette (C-E3-E2-6K-E1), the spike vaccine encoded a truncated and modified segment (E3-E2 $\Delta T M-$ linker-E1 $\Delta \mathrm{TM})$. Recombinant baculoviruses were generated to express CHIKV spikes (Ac-Spike) or spikes with a furin cleavage site mutation (Ac-Spike $\Delta F$ ) to maintain a prefusion state. Both spikes were Strep-tagged and expressed in adherent and suspension insect cells. The secreted spikes were purified from the culture fluid and analyzed for trimerization and glycosylation status.

\section{Materials and Methods}

\subsection{Cells and Viruses}

Adherent Spodoptera frugiperda 21 (Sf21) cells (Invitrogen, Waltham, MA, USA) were maintained as a monolayer in Grace's Insect Medium (Gibco, Waltham, MA, USA) supplemented with $10 \%$ fetal bovine serum (FBS, Invitrogen). Sf9 suspension cells (Invitrogen) were cultured in Sf-900 II serum-free medium (Gibco) supplemented with 1\% penicillin streptomycin (P/S, Gibco) in shake flasks (Nalgene, Rochester, NY, USA) at a shaking frequency of 100 RPM. Adherent Sf9 easy titration (Sf9-ET) cells [20] were maintained in Sf-900 II medium (Gibco) supplemented with 5\% FBS (Invitrogen), $50 \mu \mathrm{g} / \mathrm{mL}$ Gentamicin (Gibco), and $100 \mu \mathrm{g} / \mathrm{mL}$ G418 Geneticin (Gibco). All cells were incubated at $27^{\circ} \mathrm{C}$.

Recombinant baculoviruses expressing secreted CHIKV spikes were generated using the Bac-to-Bac expression system. The CHIKV S27 E3E2 and E1 ectodomains were connected by a glycine-serine linker ((GGGGS $\left.)_{4}\right)$, coupled to a Step-tag II sequence at the C-terminus, and flanked by attB sites for Gateway cloning (Figure S1). Additionally, a mutated furin cleavage site fragment was generated by an E3 R65A mutation. The fragments were cloned into the pDONR207 plasmids (Invitrogen), transferred to the pDEST8 plasmids (Invitrogen), and finally transposed into the Autographa californica multiple nucleopolyhedrovirus (AcMNPV) bacmid backbone. The recombinant baculovirus backbones were transfected into Sf21 cells using ExpresS ${ }^{2}$ transfection reagent (ExpreS ${ }^{2}$ ion Biotechnologies, Hørsholm, Denmark), resulting in recombinant baculoviruses expressing secreted spikes 
(Ac-Spike) and secreted furin cleavage site mutant spikes (Ac-Spike $\Delta \mathrm{F}$ ). Baculovirus titers were determined by end-point dilution assays using Sf9-ET cells.

\subsection{Recombinant Protein Production and Purification}

The CHIKV spike and spike $\Delta \mathrm{F}$ complexes were produced in Sf21 adherent and Sf9 suspension cells after infection of the Ac-Spike and Ac-Spike $\Delta \mathrm{F}$. Sf21 cells were infected at $60 \%$ confluency with a multiplicity of infection (MOI) of $5 \mathrm{TCID}_{50} /$ cell in serum-free Grace's medium supplemented with 1\% P/S. Sf9 suspension cells were infected at a cell concentration of $2 \times 10^{6}$ cells $/ \mathrm{mL}$ with a MOI of $0.01 \mathrm{TCID}_{50} /$ cell in serum-free Sf-900 II medium supplemented with $1 \% \mathrm{P} / \mathrm{S}$ in $125 \mathrm{~mL}$ shake flasks with a working volume of $25 \mathrm{~mL}$. Cell suspensions were harvested and centrifuged $(1500 \times g, 5 \mathrm{~min})$ to separate the medium and cell fraction. The cell fraction was dissolved in phosphate-buffered saline (PBS) for protein analysis. The medium fraction was acetone precipitated for Western blotting, or stored as supernatant for Strep-Tactin affinity column purification, furin cleavage site analysis, PNGase F treatment, or baculovirus titrations.

The Strep-tagged spikes and spikes $\Delta \mathrm{F}$ were purified by their high selective affinity to Step-Tactin. The protein extract in medium fractions was filtered $(0.2 \mu \mathrm{m}$ filter Sartorius Stedim), loaded on a Strep-Tactin affinity column (Strep-Tactin XT Starter Kit (IBA Lifesciences, Gottingen, Germany)) and eluted in three fractions according to the manufacturer's protocol. The collected elution fractions were used for baculovirus titrations, bis(sulfosuccinimidyl)suberate cross-linking, Western blotting and LC-MS/MS-based glycoproteomic analysis.

\subsection{Furin Cleavage Site Analysis}

The mutation in the spike $\Delta \mathrm{F}$ sequence was analyzed by polymerase chain reaction (PCR) on the recombinant baculovirus DNA using specific CHIKV E3E2 forward (5'- ATGAGTCTTGCCATCCCAGTTATGT- $\left.{ }^{\prime}\right)$ and reverse (5'-CTCATAATAGTACAAGAT TATCTCA-3') primers. The PCR product was digested with NheI restriction enzyme (New England Biolabs, Ipswich, MA, USA) and loaded on agarose gel to verify the mutation in the furin cleavage site.

\subsection{PNGase F Treatment}

Protein glycosylation was verified by PNGase F treatment (New England Biolabs), which removes high-mannose, hybrid, and complex N-glycans from glycoproteins. Medium fractions were treated with a denaturing buffer $\left(95^{\circ} \mathrm{C}, 10 \mathrm{~min}\right)$, followed by incubation with glycobuffer G7, NP-40 buffer, and PNGase F in MQ for $2 \mathrm{~h}$ at $37^{\circ} \mathrm{C}$. Both the untreated medium samples, and those treated with PNGase F, were analyzed using Western blotting.

\subsection{Bis(Sulfosuccinimidyl)Suberate Cross-Linking}

Bis(sulfosuccinimidyl)suberate (BS3) cross-linking was performed to determine the oligomeric state of the BEVS-expressed CHIKV spikes. The recombinant proteins were incubated at room temperature in the presence of 2.5 or $5 \mathrm{mM}$ BS3 (Thermo Fisher Scientific, Waltham, MA, USA) for one hour. Thereafter, $1 \mathrm{M}$ Tris- $\mathrm{HCl} \mathrm{pH} 8.0$ was added in a final concentration of $50 \mathrm{mM}$ to stop the cross-linking reaction. The cross-linked samples were analyzed using Western blotting.

\subsection{Western Blotting}

To analyze the expressed proteins, the samples were first denatured by incubation in loading buffer containing $\beta$-mercapto-ethanol or DTT $\left(95^{\circ} \mathrm{C}, 5 \mathrm{~min}\right)$. Subsequently, the proteins were separated by sodium dodecyl sulphate-polyacrylamide gel electrophoresis (SDS-PAGE) and stained using Coomassie Brilliant Blue (CBB) staining or transferred to an Immobilon-P membrane (Millipore, Burlington, MA, USA) for Western blot analysis.

Baculovirus and CHIKV proteins were visualized by colorimetric Western blot detection. The protein membranes were blocked in $1 \%$ skimmed milk in PBS with $0.05 \%$ 
Tween 20 (PBST, Sigma, St. Louis, MI, USA) for one hour. Thereafter, the membranes were incubated with rabbit polyclonal $\alpha$-CHIKV E2 $\Delta$ TM $(1: 20,000)$, rabbit polyclonal $\alpha-C H I K V$ $\operatorname{E1} \Delta \mathrm{TM}(1: 15,000)$, or mouse polyclonal $\alpha$-baculovirus GP64 (1:1000) antibodies diluted in blocking buffer for one hour. The coated membranes were washed $3 \times 5$ min with PBST and subsequently incubated in alkaline phosphatase (AP)-conjugated goat $\alpha$-rabbit IgG (1:2500) (Dako) or AP-conjugated goat $\alpha$-mouse IgG (1:2500) (Sigma) monoclonal antibodies in PBST for one hour. After washing the membrane once again, the membranes were incubated in AP buffer for $10 \mathrm{~min}$. Finally, the proteins on the membrane were visualized by NBT/BCIP staining (Roche). The protein expression levels on the membrane were determined using the Image Studio Lite software (LI-COR).

Strep-tagged proteins were detected using chemiluminescence Western blotting. The protein membranes were air dried for one hour and washed $3 \times 5 \mathrm{~min}$ in PBST. The membranes were incubated in St-HRP $(1: 100,000)$ (Strep-TactinXT Starter Kit, IBA Lifesciences, Gottingen, Germany) diluted in PBST for one hour. After incubation, the membranes were washed $2 \times 1 \mathrm{~min}$ in PBST and $1 \times 1 \mathrm{~min}$ in PBS. The chemiluminescence reaction was developed using the Amersham Enhanced Chemiluminescence Detection Reagent Kit (General Electric Healthcare Life Sciences, Chicago, IL, USA) according to the manufacturer's protocol. The proteins on the membrane were visualized using the ChemiDoc MP (Bio-Rad, Hercules, CA, USA).

\subsection{LC-MS/MS-Based Glycoproteomic Analysis}

CHIKV protein digestion by trypsin was performed according to a filter-aided sample preparation (FASP) procedure. Briefly, between 60 and $100 \mu \mathrm{g}$ of CHIKV spike proteins were concentrated using Microcon $10 \mathrm{kDa}$ cutoff filters. The concentrated proteins were then dissolved on the filter in $8 \mathrm{M}$ urea (100mM Tris-HCL, pH 7.5) and used for trypsin digestion before reduction ( $5 \mathrm{mM}$ dithiothreitol; $30 \mathrm{~min}$ at RT) and alkylation (15 $\mathrm{mM}$ iodoacetamide; $30 \mathrm{~min}$ at RT in the dark) of the cysteines. After dilution with $0.1 \mathrm{M}$ ammonium bicarbonate, $20 \mu \mathrm{L}$ of Pierce Trypsin $(0.05 \mu \mathrm{g} / \mu \mathrm{L}$, Thermo Scientific) was added for overnight incubation at $37^{\circ} \mathrm{C}$. After digestion, peptides were recovered from the filters by centrifugation using $0.1 \%(v / v)$ trifluoroacetic acid. The tryptic digests were cleaned by reverse phase solid phase extraction on Pierce C18 Tips (100ul, Thermo Scientific) and dried by vacuum centrifugation.

Peptide eluates were dissolved in $40 \mu \mathrm{L}$ of $2 \%$ acetonitrile $0.1 \%$ formic acid solution and $2 \mu \mathrm{L}$ was injected onto an M-class UPLC (Waters, Milford, MA, USA), trapped onto a PepSep trap column $(2 \mathrm{~cm} \times 100 \mu \mathrm{m}$ ID, product \# PSC21003, PepSep. Using a $65 \mathrm{~min}$ gradient from $2 \%$ to $18 \%$ (30 $\mathrm{min}$ ) to $30 \%$ (40 $\mathrm{min}$ ), and finally to $85 \%$ acetonitrile in $0.1 \%$ formic acid, peptides were separated on an analytical column $(15 \mathrm{~cm} \times 75 \mu \mathrm{m}, 1.9 \mu \mathrm{m}$ particle size (PepSep product 15-75-19-nC)) at a flow rate of $200 \mathrm{nl}$ per minute. The column effluent was on-line connected to a Q Exactive Plus using a Nanospray Flex at 2.2kV spray voltage. MS acquisition was performed using a DDA method with an alternating MS1 scan at resolution 70,000 in profile mode, AGC target 3e6, maxIT $50 \mathrm{~ms}$, and a scan range of 500-1400 m/z. Subsequently, 10 MS2 scans were performed in centroid mode, resolution 17,500 , AGC target 5e4, maxIT100ms, with an isolation window of $1.6 \mathrm{~m} / \mathrm{z}$ at NCE $=28$ on with preferred peptide match ions of charges 2,3 , or 4 and a dynamic exclusion window of $30 \mathrm{~s}$.

The Byonic software package (Protein Metrics, version 3.11.3) was used for glycopeptide analysis. Trypsin was selected as the enzyme and three maximum missed cleavages were allowed. Searches were performed with a precursor mass tolerance and a fragment mass tolerance of $10 \mathrm{ppm}$. Static modifications consisted of the carbamidomethylation of cysteine residues (+57.02146 Da). Dynamic modifications consisted of the oxidation of methionine residues (+15.99492 Da), deamidation of asparagine and glutamine (+0.98402 Da), and N-glycosylation on asparagine. Oxidation and deamidation were set as "common" modifications, and N-glycosylation was set as a "rare" modification through Byonic node. One rare modification and one common modification were allowed. Common human 
biantennary N-glycan, plant N-glycan, and common O-glycan databases embedded in Byonic, which contains 114 glycan entities in total, were used. The results were filtered to a $1 \%$ protein FDR as set in the Byonic parameters. Only those glycopeptides with a Byonic score $>100$ were reported. Each $\mathrm{N}$-glycopeptide identified should have the consensus motif $\mathrm{NX} / \mathrm{T} / \mathrm{S}, \mathrm{X} /=\mathrm{P}$. The relative glycan abundance (\%) was calculated by dividing the number of observations for each glycoform by the total number of observations of all glycoforms and multiplying by 100.

\section{Results}

\subsection{Expression of Trimeric, Glycosylated Chikungunya Virus Spikes in Insect Cells}

Recombinant baculoviruses (Ac-Spike and Ac-Spike $\Delta F$ ) were generated to produce secreted trimeric CHIKV spikes by expression of the precursor heterodimer ectodomains. The E3E2 and E1 ectodomains were connected by a glycine-serine linker ((GGGGS $\left.{ }_{4}\right)$ in place of the C-terminal transmembrane domain of E2 and 6K (Figure 1). At the C-terminus, in place of the transmembrane domain of E1, a Strep-tag II sequence was added, allowing for Strep-Tactin affinity column purification. Furthermore, a furin cleavage site mutation $(\Delta \mathrm{F})$ was engineered to block the processing of the E3-E2 peptide and prevent low $\mathrm{pH}$ induced conformational changes of the spike. As a consequence, cell membrane fusion is hindered. It was hypothesized that retaining the spike in the pre-fusion state would enhance the immunogenicity [21-23].

Native spike

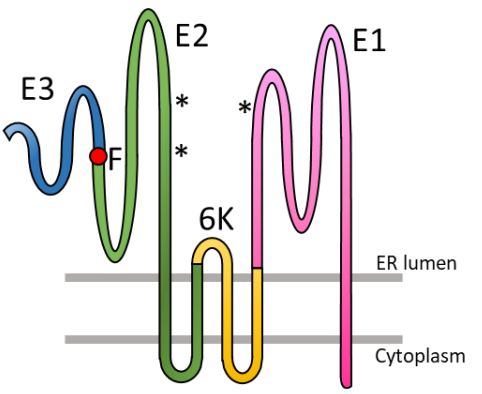

Secreted spike

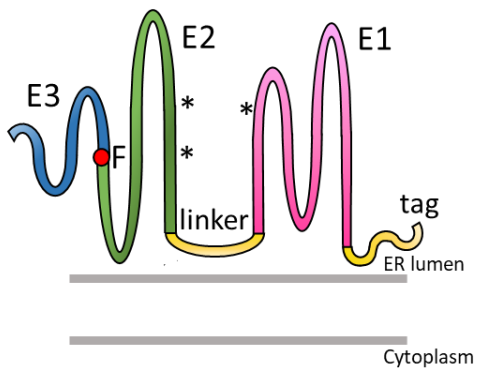

Secreted spike $\Delta F$

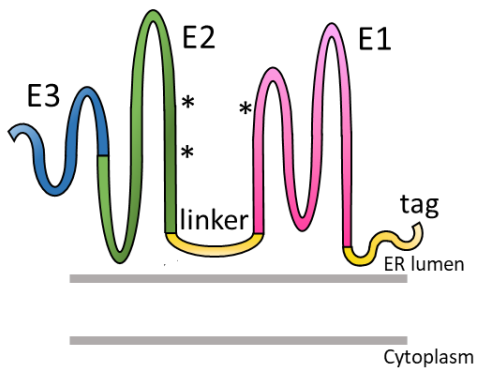

Figure 1. Native and secreted spike heterodimer precursors. The native spike heterodimer precursor, E3-E2-6K-E1, is anchored in the endoplasmic reticulum (ER) membrane and contains a furin cleavage site (F) between E3 and E2. Secreted spikes are formed by connecting the CHIKV E3E2 and E1 ectodomains with a glycine-serine linker to replace the E2 transmembrane domain and $6 \mathrm{~K}$. The C-terminal E1 transmembrane domain is replaced by a Strep-tag II (tag) sequence. The secreted spike furin cleavage site mutant $(\Delta \mathrm{F})$ has a disrupted furin cleavage site $(\mathrm{F})$ preventing cellular furin cleavage of E3. Asterisks indicate N-glycosylation sites.

The expression of the CHIKV spikes and spikes $\Delta \mathrm{F}$ in the insect cells and secretion into the culture fluid was confirmed by Western blot using CHIKV E1- and E2-polyclonal antibodies ( $\alpha$-E1 and $\alpha$-E2) (Figure 2A). Western blot analysis showed that the spikes were produced in high abundancy in the cells and were secreted into the culture fluid. The secreted spikes could be successfully detected with both $\alpha$-E1 and $\alpha$-E2 antibodies as a large protein of almost $100 \mathrm{kDa}$. The predicted size of the secreted spike with/without furin cleavage site was $88 / 95 \mathrm{kDa}$, respectively. In the cell fraction, some additional protein bands were detected due to the aspecific binding of the antiserum to insect cell and/or baculovirus proteins. 
A

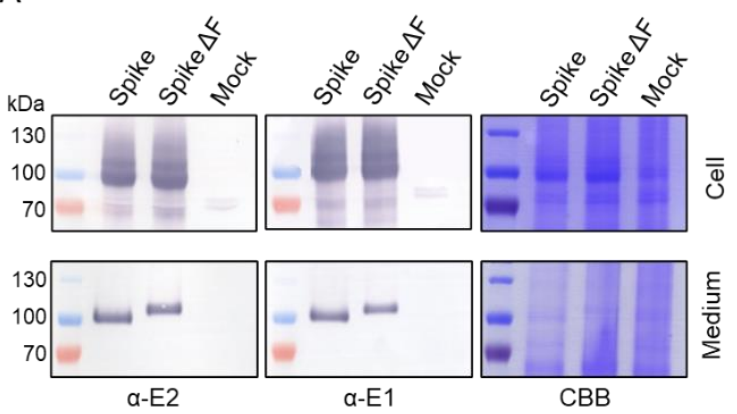

C

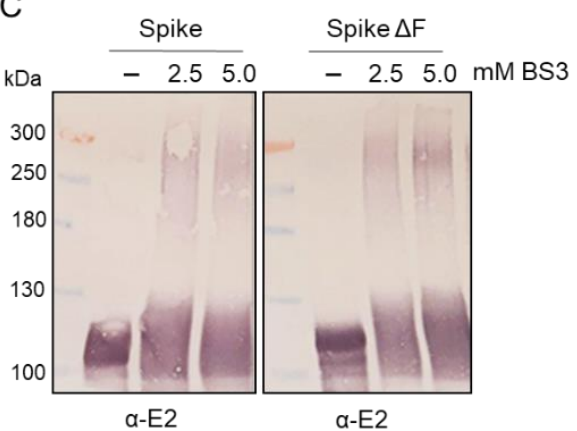

B
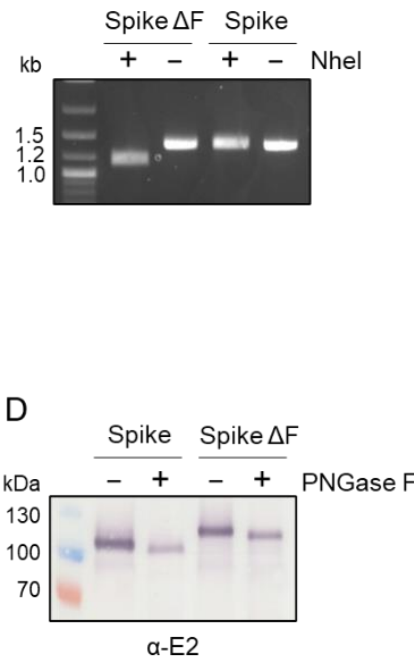

Figure 2. Secreted, glycosylated trimeric CHIKV spikes with and without furin cleavage site $(\Delta \mathrm{F})$. Adherent Sf21 cells were uninfected (mock) or infected with Ac-Spike or Ac-Spike $\Delta \mathrm{F}$. (A) Recombinant baculovirus expressed proteins in the cell and medium fraction were analyzed by Coomassie Brilliant Blue (CBB) staining and Western blotting using CHIKV E1 and E2 antibodies ( $\alpha$-E2 and $\alpha$-E1). (B) The furin cleavage site mutation in the recombinant baculovirus DNA was verified by NheI restriction enzyme digestion of CHIKV E3E2 PCR fragments loaded on agarose gel. (C) The oligomeric configuration of the secreted CHIKV proteins was analyzed by $\alpha$-E2 Western blotting after 2.5 and $5.0 \mathrm{mM}$ BS3 cross-linking, and (D) the glycosylation status by $\alpha$-E2 Western blotting after PNGase F treatment.

The furin cleavage site mutation in spike $\Delta \mathrm{F}$ is designed to prevent the dissociation of E3, and to consequently 'lock' the spike in a pre-fusion conformation. The retention of $\mathrm{E} 3$ is responsible for an additional molecular mass of roughly $7 \mathrm{kDa}$ on the $\alpha$-E1 and $\alpha$-E2 Western blots of spike $\Delta \mathrm{F}$ (Figure $2 \mathrm{~A}$ ). The presence of the furin cleavage site mutation was also confirmed by restriction enzyme digestion of recombinant baculovirus DNA from the supernatant (Figure 2B). The furin cleavage site mutation (E3 R65A) introduced an NheI digestion site in the spike $\Delta \mathrm{F}$ sequence. The NheI digested spike $\Delta F$ E3E2 PCR product showed the expected smaller band of $1.1 \mathrm{~kb}$ compared to the undigested PCR product band of $1.3 \mathrm{~kb}$ observed for the NheI-treated spike E3E2 PCR product. Hence, the Western blot and restriction enzyme digestion both confirmed the furin cleavage site mutation in the spike $\Delta \mathrm{F}$ recombinant virus DNA.

The native structure of the secreted CHIKV spikes was investigated by cross-linking the protein complexes using bis(sulfosuccinimidyl)suberate (BS3). Each subunit of the multimeric CHIKV spike complex was cross-linked by amide bonds to stabilize the structure, allowing for detection of the native state on SDS-PAGE denaturing gels. Western blot analysis of the cross-linked proteins on the denaturing gel showed an additional high-molecular weight band of approximately $300 \mathrm{kDa}$, which agrees well with the predicted masses of 264 and $285 \mathrm{kDa}$ for the trimeric spikes and spikes $\Delta \mathrm{F}$ configurations, respectively (Figure 2C). Furthermore, smaller protein configurations were detected for the BS3 cross-linked samples, likely corresponding to internally cross-linked spike monomers. These were either secreted monomers, or the result of product degradation during the purification and crosslinking procedure. Although a substantial monomer fraction was detected, the Western blots indicate that at least a fraction of the recombinant spikes are trimerized. 
Lastly, the glycosylation status of the insect cell-expressed secreted trimeric CHIKV proteins was determined. Three N-glycosylation sites have been predicted for CHIKV glycoproteins: one on E1 (N141) and two on E2 (N263 and N273) [12]. The N-glycosylation was first evaluated using a PNGase F treatment, which enzymatically removes glycan residues from $\mathrm{N}$-glycosylated proteins. The PNGase F-treated spike and spike $\Delta \mathrm{F}$ showed a reduction in molecular mass compared to the untreated samples on an $\alpha$-E2 Western blot (Figure 2D). This reduction in molecular mass, caused by the removal of the glycan residues, indicated that the expressed glycoproteins are N-glycosylated. LC-MS/MS-based glycoproteomic analysis demonstrated that the majority are of the mannose- or hybrid-type $\mathrm{N}$-glycans, and a minor proportion of the N-glycans $(<2 \%)$ have a complex-type structure, as expected for insect cell-expressed glycoproteins (Figure 3). Only small differences in $\mathrm{N}$-glycan composition were observed between the spikes and spikes $\Delta \mathrm{F}$. The latter showed a slightly higher abundancy of mannose-type N-glycans. The mass spectrometry analysis also revealed three O-glycosylation sites in E1, each site occupied with one glycan type (T206 HexHAc(2), S266 HexNAc(2), and T315 HexNAc(1)).

A

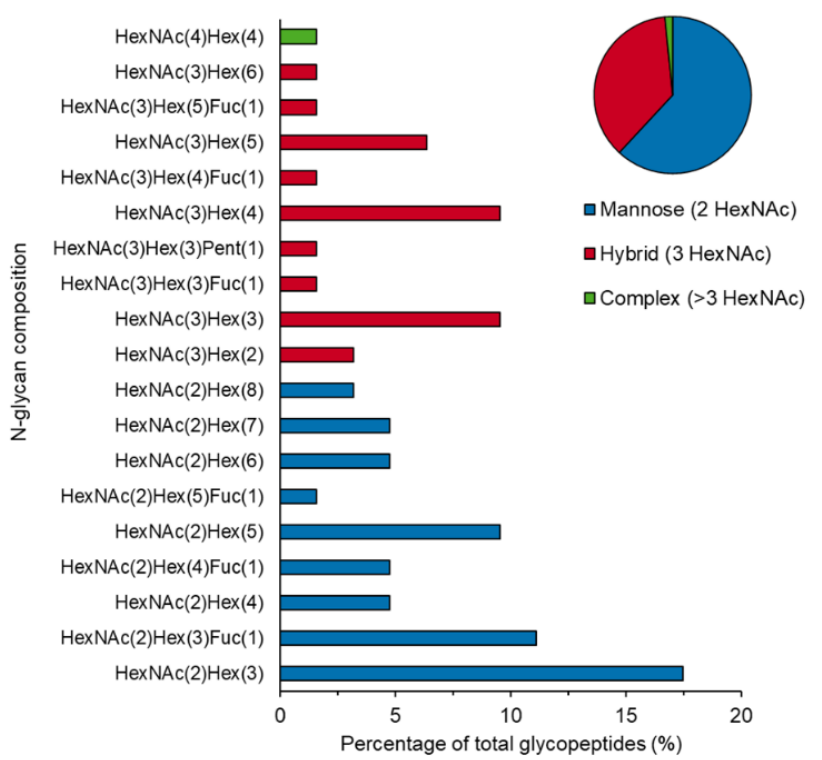

B

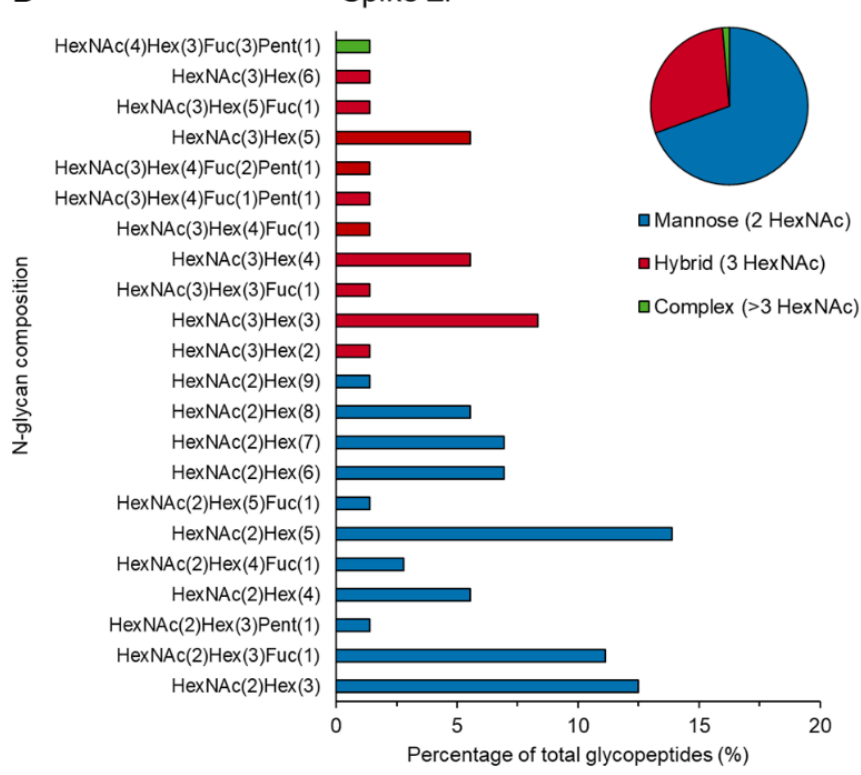

Figure 3. N-glycan composition of the CHIKV spikes with and without furin cleavage site $(\Delta \mathrm{F})$. Sf21 cells were infected with (A) Ac-Spike or (B) Ac-Spike $\Delta \mathrm{F}$, secreted spikes were purified from the culture fluid and analyzed for total N-glycan composition using LC-MS/MS-based glycoproteomic analysis. The bar graph provides a detailed description of the detected N-glycans. The pie chart represents a summary of the $\mathrm{N}$-glycan structure types.

\subsection{Production of Secreted CHIKV Spikes in Sf9 Suspension Cells}

Industrial scale production of BEVS-derived products takes place in insect cells grown in bioreactors as suspension culture. To evaluate the potential for up-scaling spike production, Sf9 suspension cells were infected in shake flasks with Ac-Spike and Ac-Spike $\Delta \mathrm{F}$ under previously determined optimized conditions based on product yield [8]. Infections were performed at a low MOI of $0.01 \mathrm{TCID}_{50} /$ cell to enable the Sf9 cells to proliferate in the first $46 \mathrm{~h}$ post infection (hpi) up to a viable cell concentration of $7.8 \times 10^{6}$ cells $/ \mathrm{mL}$ (Figure 4A). The recombinant baculovirus titers showed a similar trend in viral growth, reaching $1 \times 10^{6} \mathrm{TCID}_{50} / \mathrm{mL}$ at $46 \mathrm{hpi}$ (Figure $4 \mathrm{~B}$ ). When the baculovirus concentration plateaued from 46 hpi onwards, the viable cell concentration decreased due to baculovirusinduced cell death. The highest spike and spike $\Delta \mathrm{F}$ product yields were reached at $52 \mathrm{hpi}$ with protein concentrations of 5.8 and $7.6 \mathrm{mg} / \mathrm{L}$, respectively (Figure 4C,D). Thereafter, the spike protein concentration reduced by cell lysis induced protein degradation. Furthermore, a double band pattern appeared, suggesting the presence of glycosylated and 
non-glycosylated spikes. Based on the quantified protein concentrations, spikes and spikes $\Delta \mathrm{F}$ produced in Sf9 suspension cells should be harvested around 50 hpi to generate optimal product yields.

A

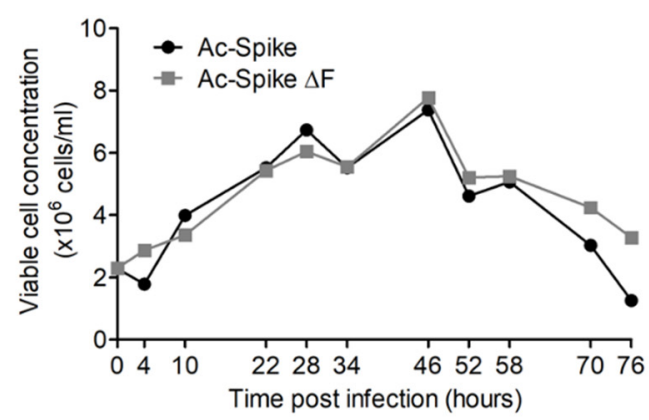

C

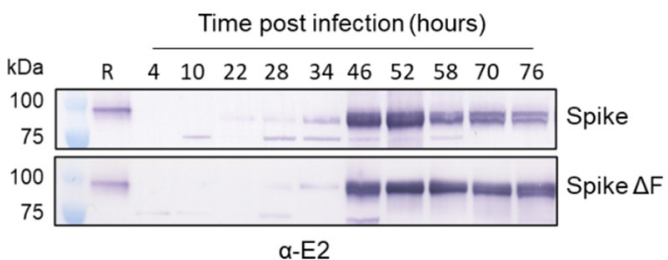

B

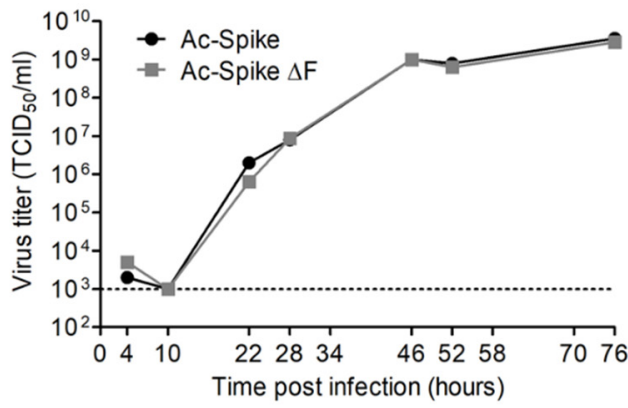

D

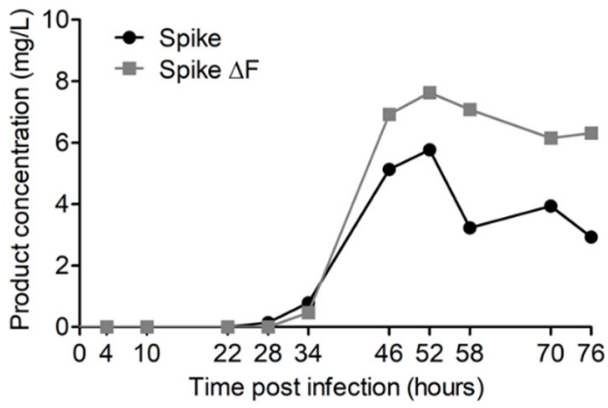

Figure 4. Spike and spike $\Delta \mathrm{F}$ production in suspension insect cells. The Sf9 suspension cells were infected with Ac-Spike and Ac-Spike $\Delta \mathrm{F}$ at a cell concentration of $2 \times 10^{6}$ cells $/ \mathrm{mL}$ and MOI of $0.01 \mathrm{TCID}_{50} /$ cell in $200 \mathrm{~mL}$ shake flasks. Samples were taken at various time points to evaluate (A) the viable cell concentration by hemocytometer cell count with trypan blue staining, (B) recombinant baculovirus titers by end-point dilution assay (threshold indicated by dotted line), and (D) spike and spike $\Delta \mathrm{F}$ product concentrations quantified by $(\mathrm{C})$ relative expression to purified CHIKV E3E2 subunit reference sample (R) on an $\alpha$-E2 Western blot.

\subsection{Downstream Processing by Strep-Tactin Affinity Column Purification}

The recombinant baculoviruses Ac-Spike and Ac-Spike $\Delta \mathrm{F}$ were engineered with a Strep-tag II at the C-terminus of the E1 protein replacing the transmembrane domain. The presence of the Strep-tag was confirmed by a Strep-tag conjugate St-HRP and a CHIKV $\alpha$-E2 Western blot (Figure 5A). The Strep-tag bands on the St-HRP Western blot corresponded with the spike and spike $\Delta \mathrm{F}$ bands on the $\alpha$-E2 Western blot, demonstrating that the spikes and the spikes $\Delta \mathrm{F}$ were indeed Strep-tagged.

The Strep-tagged spikes were purified using a Strep-Tactin affinity column to clear other proteins and contaminating baculoviruses from the spike product. The spike proteins were bound to the Strep-Tactin column, washed three times, and eluted in three fractions of $0.6,1.6$, and $0.8 \mathrm{~mL}$ to retain the main protein content in the second elution fraction. The elution and wash fractions were analyzed for the presence of CHIKV proteins by $\alpha$-E2 Western blot (Figure 5B), baculovirus proteins by $\alpha$-GP64 Western blot (Figure 5B), and infectious baculoviruses by viral titrations (Figure 5C). The $\alpha$-E2 and $\alpha$-GP64 Western blots showed that $70 \%$ of the CHIKV proteins were retained in the second elution fraction (protein concentration of $1.32 \mathrm{mg} / \mathrm{L}$ ) without a detectable presence of baculovirus GP64 proteins (Figure 5B). The contaminating baculoviruses were efficiently cleared by the first wash step. Although baculovirus proteins were not detected in the elution fractions by Western blotting, infectious baculoviruses were detected in the second and third elution fraction by viral titrations. Nonetheless, the baculovirus titers in the elution fractions were 
reduced by $99.98 \%$ in comparison to the filtered input fraction. This demonstrated that the Strep-Tactin affinity purification process efficiently clears contaminating baculoviruses from the spike products.

A
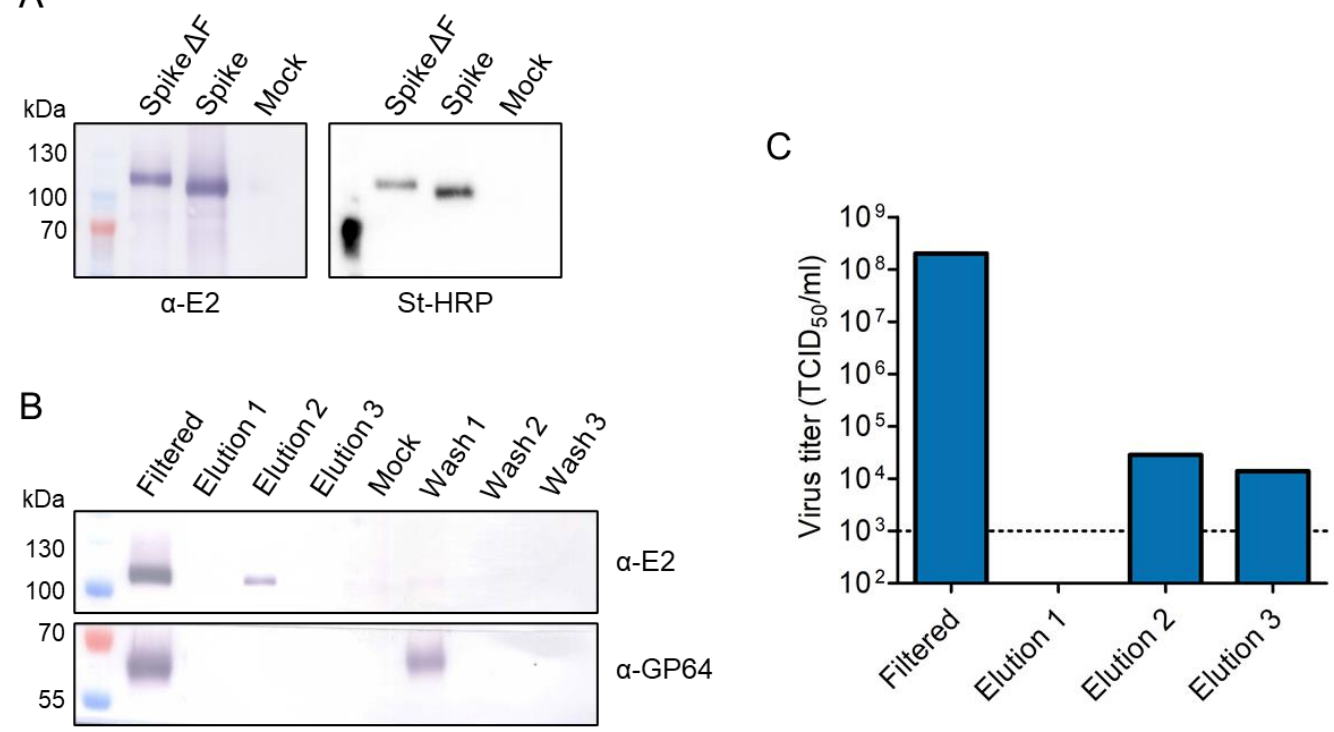

Figure 5. Strep-Tactin affinity column purification of Strep-tagged spikes. Sf21 cells were infected with Ac-Spike and Ac-Spike $\Delta \mathrm{F}$. Medium fractions were harvested, $0.2 \mu \mathrm{m}$ filtered and purified using a Strep-Tactin affinity column. (A) Secreted proteins in the filtered medium fraction were analyzed on a CHIKV $\alpha$-E2 Western blot and Strep-tag-conjugated St-HRP Western blot. (B) Secreted proteins in the filtered medium, and Strep-Tactin wash and elution fractions were analyzed on a CHIKV $\alpha$-E2 Western blot and baculovirus $\alpha$-GP64 Western blot. (C) Baculovirus titers in the filtered medium and Strep-Tactin elution fractions were determined by end-point dilution assay (threshold indicated by dotted line).

\section{Discussion}

This study describes the expression and purification of secreted trimeric CHIKV spikes from insect cells. The E3E2-E1 ectodomains of CHIKV were connected by a flexible linker and cloned downstream of the polyhedrin promotor of a recombinant baculovirus. To preserve the stable pre-fusion configuration of the immature spike, a furin cleavage site mutation (Ac-Spike $\Delta \mathrm{F}$ ) was introduced to prevent the cleavage between E3 and E2. Western analysis of the medium fraction showed that the CHIKV protein complexes were secreted in high abundancy; in the mature, furin-cleaved (spike) or immature (spike $\Delta \mathrm{F}$ ) form. The immature spikes were produced at a higher concentration than the mature, furincleaved spikes, which might be a result of increased $\mathrm{pH}$ insensitivity, similar to observations by others [24]. BS3 cross-linking analysis showed that the spike monomers self-assembled into trimeric spikes. Comparable strategies were used by others to generate secreted alphavirus spikes in a mature and immature form, which showed remarkable similarities in crystal structure to the trimeric spikes of the native virion [14,23]. Furthermore, the $\mathrm{N}$-glycosylation of the spikes produced in adherent insect cells was confirmed by a shift in protein size on Western blot after PNGase F treatment, and by LC-MS/MS glycoproteomicbased analysis. As no additional bands appeared on the Western blot for these spikes, this indicated that no processing intermediates were secreted from the adherent insect cells, so all heterodimers were expected to be completely glycosylated. This corresponds with previous research presenting increased processing efficiency of CHIKV proteins when the glycoproteins E1 and E3E2 were co-expressed as part of a polyprotein in comparison to subunits [12,13]. Overall, this suggests that the recombinant baculovirus expression vectors expressed secreted trimeric CHIKV spikes and furin cleavage site mutant spikes that are 
similar in polymeric state and glycosylation to mature and immature spikes, respectively, displayed on the native CHIKV virion.

The well-established BEVS in insect cells allows for the scalable production of complex proteins. Here, CHIKV spikes were generated in shake flasks, but this can easily be increased to bioreactor volumes $[8,25]$. Industrial-scale manufacturing processes for $2500 \mathrm{~L}$ bioreactors have been developed for licensed BEVS-derived vaccines and therapeutics [26-28]. The final production scale is largely dependent on the product yield, which can be further optimized for the production of CHIKV spikes. We previously studied the synergy between the multiplicity of infection, cell concentration of infection, and time of harvesting [8]. However, adapting other factors such as production cell line, medium composition, and process mode (e.g., fed batch) can further increase yields as shown for other recombinant baculovirus-generated protein complexes [29-32]. This highlights the opportunities for development and optimization of a large-scale production process for baculovirus-derived CHIKV spikes in insect cells.

One of major challenges for baculovirus-derived human vaccines is the required clarification of co-produced budded baculoviruses during downstream processing. To clear these contaminating baculoviruses from the CHIKV spike product, a Strep-Tactin affinity column purification was performed. This greatly reduced the residual baculovirus material, whereas the Strep-tagged spikes were successfully regenerated from the column. To improve downstream processing and product quality, a protease cleavage site can be engineered just upstream of the Strep-tag to remove the tag after purification, as we have recently done for SARS-CoV-2 spike antigens [25]. Alternative large-scale purification methods such as tangential flow filtration and chromatography can be applied as well, since the CHIKV spikes and co-produced baculoviruses differ in physical properties (size, charge, and density). Moreover, novel virion-free strategies are in development to reduce extensive downstream processing by decreasing the contaminating baculoviruses in the production phase [33]. Overall, a scalable and cost-effective downstream process should be designed to extract a pure and high-quality vaccine product.

A critical next step to access the feasibility of the secreted trimeric CHIKV spikes as a vaccine candidate is the investigation of the immunogenicity of the spikes. Previous studies on CHIKV VLPs presented strong neutralizing antibody responses, broad cellular immune responses, and disease protection in mice, non-human primates, and humans, without any safety or tolerance issues [12,13,24,34-39]. The induced immune responses were mainly directed against the epitopes on the E1 and E2 glycoproteins [37,39,40]. Although the E1 and E2 epitope configuration of the BEVS-derived secreted trimeric CHIKV spikes requires more research, similar immune responses are expected based on adenovirus vector-expressed trimeric CHIKV spike in vivo studies. These adenovirus vector-expressed trimeric CHIKV spikes induced the same neutralizing antibody responses and protection as adenovirus vector-expressed CHIKV VLPs [41,42]. Furthermore, the insect cell-expressed CHIKV trimeric spikes can also be presented in a VLP configuration by coupling the spikes to nanoparticles via a SpyTag-SpyCatcher conjugation. This multimeric presentation of antigens increased neutralizing antibody responses for SARS-CoV-2 spikes and Rift Valley fever virus glycoprotein head domains [25,43-45]. We also developed a furin cleavage site mutant to maintain the spike in a pre-fusion state. It is hard to predict the effect of the E3 retention on the spike on the overall immunogenicity, but it has been reported that E3 can also induce neutralizing antibodies [46]. Furthermore, a previous study on CHIKV VLPs showed that such a mutation increased the immunogenicity of the vaccine candidate [21]. Additional research is required to verify and compare the immunogenicity of the spike and furin mutant spike.

This study forms a proof of principle for BEVS-derived secreted trimeric alphavirus spike vaccine antigens, which overcome the downstream processing challenges of VLP vaccines but have a similar epitope configuration. As the genome composition and spike folding of alphaviruses is comparable, this vaccine antigen strategy can also be applied for other threatening alphaviruses, e.g., Mayaro virus and O'nyong'nyong virus, and 
potentially for multivalent vaccine mixes to protect against co-circulating alphavirus infections [38]. As the trimeric CHIKV spike strategy forms the perfect intermediate between subunit and VLP vaccines, we propose further development of BEVS-derived alphavirus trimeric spike vaccine antigens as safe and effective vaccine candidates to protect humans against CHIKV and other alphavirus outbreaks.

Supplementary Materials: The following are available online at https://www.mdpi.com/article/10.3 390/pr10010162/s1, Figure S1: Native and secreted spike heterodimer precursors amino acid alignment.

Author Contributions: Conceptualization, G.P.P. and S.W.M.; investigation, C.G., M.G.L.H. and T.A.H.H.; writing—original draft preparation, T.A.H.H.; writing—review and editing, C.G., M.G.L.H., D.E.M., S.W.M. and G.P.P.; visualization, T.A.H.H.; supervision, D.E.M. and G.P.P. All authors have read and agreed to the published version of the manuscript.

Funding: This research received no external funding.

Institutional Review Board Statement: Not applicable.

Informed Consent Statement: Not applicable.

Conflicts of Interest: The authors declare no conflict of interest.

\section{References}

1. Borgherini, G.; Poubeau, P.; Jossaume, A.; Gouix, A.; Cotte, L.; Michault, A.; Arvin-Berod, C.; Paganin, F. Persistent Arthralgia Associated with Chikungunya Virus: A Study of 88 Adult Patients on Reunion Island. Clin. Infect. Dis. 2008, 47, 469-475. [CrossRef]

2. Wahid, B.; Ali, A.; Rafique, S.; Idrees, M. Global expansion of chikungunya virus: Mapping the 64-year history. Int. J. Infect. Dis. 2017, 58, 69-76. [CrossRef]

3. Gao, S.; Song, S.; Zhang, L. Recent Progress in Vaccine Development Against Chikungunya Virus. Front. Microbiol. 2019, 10, 2881. [CrossRef]

4. Schrauf, S.; Tschismarov, R.; Tauber, E.; Ramsauer, K. Current Efforts in the Development of Vaccines for the Prevention of Zika and Chikungunya Virus Infections. Front. Immunol. 2020, 11, 592. [CrossRef]

5. Van Oers, M.M.; Pijlman, G.P.; Vlak, J.M. Thirty years of baculovirus-insect cell protein expression: From dark horse to mainstream technology. J. Gen. Virol. 2015, 96, 6-23. [CrossRef]

6. Chen, N.; Kong, X.; Zhao, S.; Xiaofeng, W. Post-translational modification of baculovirus-encoded proteins. Virus Res. 2020, 279, 197865. [CrossRef]

7. van Oers, M.M. Opportunities and challenges for the baculovirus expression system. J. Invertebr. Pathol. 2011, 107, S3-S15. [CrossRef]

8. Pijlman, G.P.; Grose, C.; Hick, T.A.H.; Breukink, H.E.; Braak, R.V.D.; Abbo, S.R.; Geertsema, C.; Van Oers, M.M.; Martens, D.E.; Esposito, D. Relocation of the attTn7 Transgene Insertion Site in Bacmid DNA Enhances Baculovirus Genome Stability and Recombinant Protein Expression in Insect Cells. Viruses 2020, 12, 1448. [CrossRef]

9. Sun, B.; Zhao, D.; Zhang, X.; Gu, T.; Yu, X.; Sun, S.; Zhao, X.; Wei, L.; Liu, D.; Yan, H.; et al. Development a scalable production process for truncated human papillomavirus type-6 L1 protein using WAVE Bioreactor and hollow fiber membrane. Appl. Microbiol. Biotechnol. 2015, 100, 1231-1240. [CrossRef]

10. Wagner, J.M.; Pajerowski, J.D.; Daniels, C.L.; McHugh, P.M.; Flynn, J.A.; Balliet, J.W.; Casimiro, D.R.; Subramanian, S. Enhanced production of chikungunya virus-like particles using a high-pH adapted Spodoptera frugiperda insect cell line. PLoS ONE 2014, 9, e94401.

11. Weber, W.; Weber, E.; Geisse, S.; Memmert, K. Optimisation of protein expression and establishment of the Wave Bioreactor for Baculovirus/insect cell culture. Cytotechnology 2002, 38, 77-85. [CrossRef]

12. Metz, S.W.; Gardner, J.; Geertsema, C.; Le, T.T.; Goh, L.; Vlak, J.M.; Suhrbier, A.; Pijlman, G.P. Effective Chikungunya Virus-like Particle Vaccine Produced in Insect Cells. PLoS Neglected Trop. Dis. 2013, 7, e2124. [CrossRef] [PubMed]

13. Metz, S.W.; Martina, B.E.; Doel, P.V.D.; Geertsema, C.; Osterhaus, A.; Vlak, J.M.; Pijlman, G. Chikungunya virus-like particles are more immunogenic in a lethal AG129 mouse model compared to glycoprotein E1 or E2 subunits. Vaccine 2013, 31, $6092-6096$. [CrossRef]

14. Voss, J.E.; Vaney, M.-C.; Duquerroy, S.; Vonrhein, C.; Girard-Blanc, C.; Crublet, E.; Thompson, A.; Bricogne, G.; Rey, F. Glycoprotein organization of Chikungunya virus particles revealed by X-ray crystallography. Nature 2010, 468, 709-712. [CrossRef] [PubMed]

15. Kuhn, R.J. Togaviridae: The viruses and their replication. In Fields Virology; Knipe, D.M., Howley, P.M., Eds.; Lippincott Williams and Wilkins: Baltimore, MD, USA, 2007; pp. 1001-1022.

16. Mulvey, M.; Brown, D.T. Assembly of the Sindbis Virus Spike Protein Complex. Virology 1996, 219, 125-132. [CrossRef]

17. Zhang, X.; Fugère, M.; Day, R.; Kielian, M. Furin Processing and Proteolytic Activation of Semliki Forest Virus. J. Virol. 2003, 77, 2981-2989. [CrossRef] 
18. Sjöberg, M.; Lindqvist, B.; Garoff, H. Activation of the alphavirus spike protein is suppressed by bound E3. J. Virol. 2011, 85, 5644-5650. [CrossRef]

19. Yap, M.L.; Klose, T.; Urakami, A.; Hasan, S.S.; Akahata, W.; Rossmann, M.G. Structural studies of Chikungunya virus maturation. Proc. Natl. Acad. Sci. USA 2017, 114, 13703-13707. [CrossRef]

20. Hopkins, R.F.; Esposito, D. A rapid method for titrating baculovirus stocks using the Sf-9 Easy Titer cell line. BioTechniques 2009, 47, 785-788. [CrossRef]

21. Urakami, A.; Sakurai, A.; Ishikawa, M.; Yap, M.L.; Flores-Garcia, Y.; Haseda, Y.; Aoshi, T.; Zavala, F.P.; Rossmann, M.G.; Kuno, S.; et al. Development of a Novel Virus-Like Particle Vaccine Platform That Mimics the Immature Form of Alphavirus. Clin. Vaccine Immunol. 2017, 24, e00090-17. [CrossRef]

22. Akahata, W.; Nabel, G.J. A Specific Domain of the Chikungunya Virus E2 Protein Regulates Particle Formation in Human Cells: Implications for Alphavirus Vaccine Design. J. Virol. 2012, 86, 8879-8883. [CrossRef] [PubMed]

23. Li, L.; Jose, J.; Xiang, Y.; Kuhn, R.J.; Rossmann, M.G. Structural changes of envelope proteins during alphavirus fusion. Nature 2010, 468, 705-708. [CrossRef]

24. Akahata, W.; Yang, Z.-Y.; Andersen, H.; Sun, S.; Holdaway, H.A.; Kong, W.-P.; Lewis, M.G.; Higgs, S.; Rossmann, M.G.; Rao, S.; et al. A virus-like particle vaccine for epidemic Chikungunya virus protects nonhuman primates against infection. Nat. Med. 2010, 16, 334-338. [CrossRef]

25. Van Oosten, L.; Altenburg, J.J.; Fougeroux, C.; Geertsema, C.; Den End, F.; Evers, W.A.C.; Westphal, A.H.; Lindhoud, S.; van den Berg, W.; Swarts, D.C.; et al. Two-component nanoparticle vaccine displaying glycosylated spike S1 domain induces neutralizing antibody response against SARS-CoV-2. MBio 2021, 12, e01813-21. [CrossRef] [PubMed]

26. Buckland, B.; Boulanger, R.; Fino, M.; Srivastava, I.; Holtz, K.; Khramtsov, N.; McPherson, C.; Meghrous, J.; Kubera, P.; Cox, M.M Technology transfer and scale-up of the Flublok ${ }^{\circledR}$ recombinant hemagglutinin (HA) influenza vaccine manufacturing process. Vaccine 2014, 32, 5496-5502. [CrossRef]

27. Buckland, B.C. The development and manufacture of influenza vaccines. Hum. Vaccin. Immunother. 2015, 11, 1357-1360. [CrossRef]

28. Vicente, T.; Roldao, A.; Peixoto, C.; Carrondo, M.J.; Alves, P. Large-scale production and purification of VLP-based vaccines. J. Invertebr. Pathol. 2011, 107, S42-S48. [CrossRef]

29. Krammer, F.; Schinko, T.; Palmberger, D.; Tauer, C.; Messner, P.; Grabherr, R. Trichoplusia ni cells (High FiveTM) are highly efficient for the production of influenza A virus-like particles: A comparison of two insect cell lines as production platforms for influenza vaccines. Mol. Biotechnol. 2010, 45, 226-234. [CrossRef]

30. Ikonomou, L.; Schneider, Y.-J.; Agathos, S.N. Insect cell culture for industrial production of recombinant proteins. Appl. Microbiol. Biotechnol. 2003, 62, 1-20. [CrossRef] [PubMed]

31. Monteiro, F.; Bernal, V.; Chaillet, M.; Berger, I.; Alves, P.M. Targeted supplementation design for improved production and quality of enveloped viral particles in insect cell-baculovirus expression system. J. Biotechnol. 2016, 233, 34-41. [CrossRef]

32. Carinhas, N.; Bernal, V.; Monteiro, F.; Carrondo, M.; Oliveira, R.; Alves, P. Improving baculovirus production at high cell density through manipulation of energy metabolism. Metab. Eng. 2010, 12, 39-52. [CrossRef]

33. Marek, M.; van Oers, M.M.; Devaraj, F.F.; Vlak, J.M.; Merten, O.-W. Engineering of baculovirus vectors for the manufacture of virion-free biopharmaceuticals. Biotechnol. Bioeng. 2010, 108, 1056-1067. [CrossRef]

34. Chen, G.L.; Coates, E.E.; Plummer, S.H.; Carter, C.A.; Berkowitz, N.; Conan-Cibotti, M.; Cox, J.H.; Beck, A.; O'Callahan, M.; Andrews, C.; et al. Effect of a chikungunya virus-like particle vaccine on safety and tolerability outcomes: A randomized clinical trial. J. Am. Med. Assoc. 2020, 323, 1369-1377. [CrossRef]

35. Chang, L.-J.; Dowd, K.A.; Mendoza, F.H.; Saunders, J.G.; Sitar, S.; Plummer, S.H.; Yamshchikov, G.; Sarwar, U.N.; Hu, Z.; Enama, M.E.; et al. Safety and tolerability of chikungunya virus-like particle vaccine in healthy adults: A phase 1 dose-escalation trial. Lancet 2014, 384, 2046-2052. [CrossRef]

36. Brandler, S.; Ruffié, C.; Combredet, C.; Brault, J.-B.; Najburg, V.; Prevost, M.-C.; Habel, A.; Tauber, E.; Desprès, P.; Tangy, F. A recombinant measles vaccine expressing chikungunya virus-like particles is strongly immunogenic and protects mice from lethal challenge with chikungunya virus. Vaccine 2013, 31, 3718-3725. [CrossRef]

37. Arévalo, M.T.; Huang, Y.; Jones, C.A.; Ross, T.M. Vaccination with a chikungunya virus-like particle vaccine exacerbates disease in aged mice. PLoS Neglected Trop. Dis. 2019, 13, e0007316. [CrossRef]

38. Garg, H.; Mehmetoglu-Gurbuz, T.; Joshi, A. Virus Like Particles (VLP) as multivalent vaccine candidate against Chikungunya, Japanese Encephalitis, Yellow Fever and Zika Virus. Sci. Rep. 2020, 10, 4017. [CrossRef]

39. García-Arriaza, J.; Cepeda, V.; Hallengärd, D.; Sorzano, C.Ó.S.; Kümmerer, B.M.; Liljeström, P.; Esteban, M. A novel poxvirusbased vaccine, MVA-CHIKV, is highly immunogenic and protects mice against chikungunya infection. J. Virol. 2014, 88, 3527-3547. [CrossRef]

40. Fong, R.H.; Banik, S.S.R.; Mattia, K.; Barnes, T.; Tucker, D.; Liss, N.; Lu, K.; Selvarajah, S.; Srinivasan, S.; Mabila, M.; et al. Exposure of Epitope Residues on the Outer Face of the Chikungunya Virus Envelope Trimer Determines Antibody Neutralizing Efficacy. J. Virol. 2014, 88, 14364-14379. [CrossRef]

41. Dora, E.G.; Rossi, S.L.; Weaver, S.C.; Tucker, S.N.; Mateo, R. An adjuvanted adenovirus 5-based vaccine elicits neutralizing antibodies and protects mice against chikungunya virus-induced footpad swelling. Vaccine 2019, 37, 3146-3150. [CrossRef] 
42. López-Camacho, C.; Kim, Y.C.; Blight, J.; Moreli, M.L.; Montoya-Diaz, E.; Huiskonen, J.T.; Kümmerer, B.M.; Reyes-Sandoval, A. Assessment of Immunogenicity and Neutralisation Efficacy of Viral-Vectored Vaccines Against Chikungunya Virus. Viruses 2019, 11, 322. [CrossRef]

43. Zhang, B.; Chao, C.W.; Tsybovsky, Y.; Abiona, O.M.; Hutchinson, G.B.; Moliva, J.I.; Olia, A.S.; Pegu, A.; Phung, E.; Stewart-Jones, G.B.E.; et al. A platform incorporating trimeric antigens into self-assembling nanoparticles reveals SARS-CoV-2spike nanoparticles to elicit substantially higher neutralizing responses than spike alone. Sci. Rep. 2020, 10, 18149. [CrossRef]

44. Wichgers Schreur, P.J.; Tacken, M.; Gutjahr, B.; Keller, M.; van Keulen, L.; Kant, J.; van de Water, S.; Lin, Y.; Eiden, M.; Rissmann, M.; et al. Vaccine efficacy of self-assembled multimeric protein scaffold particles displaying the glycoprotein $\mathrm{Gn}$ head domain of rift valley fever virus. Vaccines 2021, 9, 301. [CrossRef]

45. Fougeroux, C.; Goksøyr, L.; Idorn, M.; Soroka, V.; Myeni, S.K.; Dagil, R.; Janitzek, C.M.; Søgaard, M.; Aves, K.-L.; Horsted, E.W.; et al. Capsid-like particles decorated with the SARS-CoV-2 receptor-binding domain elicit strong virus neutralization activity. Nat. Commun. 2021, 12, 324. [CrossRef]

46. Kam, Y.-W.; Lee, W.W.L.; Simarmata, D.; Harjanto, S.; Teng, T.-S.; Tolou, H.; Chow, A.; Lin, R.T.P.; Leo, Y.-S.; Rénia, L.; et al. Longitudinal Analysis of the Human Antibody Response to Chikungunya Virus Infection: Implications for Serodiagnosis and Vaccine Development. J. Virol. 2012, 86, 13005-13015. [CrossRef] 